\title{
Exploring Small Heat Shock Proteins (sHSPs) for Targeting Drug Resistance in Candida albicans and other Pathogenic Fungi
}

\author{
Rahul Dev \\ Department of Zoology, Acharya Narendra Dev College, University of Delhi, Govindpuri, Kalkaji, \\ New Delhi - 110 019, India.
}

\begin{abstract}
Fungal infections have predominantly increased worldwide that leads to morbidity and mortality in severe cases. Invasive candidiasis and other pathogenic fungal infections are a major problem in immunocompromised individuals and post-operative patients. Increasing resistance to existing antifungal drugs calls for the identification of novel antifungal drug targets for chemotherapeutic interventions. This demand for identification and characterization of novel drug targets leads to the development of effective antifungal therapy against drug resistant fungi. Heat shock proteins (HSPs) are important for various biological processes like protein folding, posttranslational modifications, transcription, translation, and protein aggregation. HSPs are involved in maintaining homeostasis of the cell. A subgroup of HSPs is small heat shock proteins (sHSPs), which functions as cellular chaperones. They are having a significant role in the many cellular functions like development, cytoskeletal organization, apoptosis, membrane lipid polymorphism, differentiation, autophagy, in infection recognition and are major players in various stresses like osmotic stress, $\mathrm{pH}$ stress, etc. Studies have shown that fungal cells express increased levels of sHSPs upon antifungal drug induced stress responses. Here we review the important role of small heat shock proteins (sHSPs) in fungal diseases and their potential as antifungal targets.
\end{abstract}

Keywords: Candida albicans, Drug resistance, Small heat shock proteins, Antifungals 


\section{INTRODUCTION}

Fungi are the most common human pathogen that causes severe cutaneous infections to life-threatening systemic infections. In the United States, hospital born Candida is a major pathogen and cause frequent systemic infections in the patients. It also causes frequent oral infection in immunocompromised individuals. There are several virulent factors like an expression of adhesion molecules, secretion of hydrolytic enzymes, biofilm formation and microenvironment conditions like $\mathrm{pH}$, nutrients which are responsible to convert non-virulent yeast form to virulent hyphal form (Polymorphism).

In major surgeries, severe cases of superficial and systemic infections of $C$. albicans are reported in immunocompromised patients ${ }^{1}$. Several groups of antifungal drugs attack or disrupt cell membrane of $C$. albicans e.g. echinocandins, polyenes, and azoles etc. ${ }^{2}$, which act as stress to the pathogen. The severity of stress condition depends upon dose and type of drug. Various receptors on the membrane of pathogenic fungi are involved to perceive this stress by eliciting various conserved signaling pathways like MAP kinase (MAPK) and calcineurin signal transduction pathways etc. ${ }^{3,4}$

In drug resistant pathogenic fungi, several counter mechanisms exist to minimize or nullify the stress produced due to exposure of antifungal agents. Fungi static drugs that inhibit growth at the minimum growth-inhibitory concentration (MIC) did not kill fungal pathogen because of the drug tolerance phenomenon ${ }^{5}$, whereas fungicidal drugs that are been used at a higher concentration than MIC did not kill drug resistant pathogens. Prolonged exposure to different fungistatic drugs can cause genetic mutation in fungal cells that leads to various mechanisms for drug resistance like overexpression of membrane efflux pump proteins, mutations in drug target enzymes, and upregulation of stress-response genes etc. ${ }^{6-8}$.

Extensive use of these anti-fungal drugs in the clinics has increased resistance and ineffectiveness against $C$. albicans infections ${ }^{9,10}$. Therefore it is an emergency to come up with new therapeutic targets that can be explored for developing novel antifungal agents against $C$. albicans ${ }^{10,11}$. Occurrences of Heat shock proteins (HSPs) are integral to almost every organism and are also highly diverse and widely distributed among fungal groups. It is been shown that under thermal stress, these proteins are getting upregulated. Expression of the heat shock proteins under heat stress is regulated by the heat shock transcription factor 1 (Hsf1) $)^{12}$. In C. albicans, Hsps are important not only for the growth but also for developing infection and virulence ${ }^{13-15}$. Stress conditions are inducive to promote the expression of heat shock proteins. Hsps interact with various cellular signaling pathways like MAPK, calcium-calcineurin, cell cycle control signaling, etc. regulating homeostasis and virulence in $C$. albicans $s^{14,16,17}$. It is been reported that inhibiting or disrupting Hsps causes growth inhibition of C. albicans, which leads to reverse tolerance to available antifungal drugs. Studies have shown their involvement to confer resistance to antifungal agents by modulating HSPs associated signaling pathways in C. albicans and other pathogenic fungi.

A group of heat shock proteins known as small heat shock proteins (sHSPs) with a molecular weight ranging from 12 to $43 \mathrm{kDa}$ gets upregulated upon non-thermal cues like oxidative and heavy metal stress ${ }^{18,19}$. SHSPs, not only act as chaperones but are involved in the many biological vital functions like development, cytoskeletal organization, apoptosis, membrane lipid polymorphism, differentiation, autophagy, and infection recognition ${ }^{20,21}$. These proteins can be used as therapeutic targets in the direction of the development of antifungal agents.

\section{Heat shock proteins (HSPs) in Fungi}

$\mathrm{Hsps}$ are integral and conserved among all living species, they respond to heat and non-thermal processes like oxidative stress and starvation that leads to stress to the organism ${ }^{22}$. These stressful conditions cause the loss of three dimensional structures of proteins and their aggregations leading to cell death. Hsps are molecular chaperones and expression of Hsps is a protective mechanism of the cell to combat these changes to ensure cell survival under the stress. There are two groups of Hsps, First is ATPdependent high molecular weight protein Hsps, having four different families (Hsp104, Hsp90, Hsp70, and Hsp60) and a second ATP-independent family of proteins - Hsp12 and Hsp21 having low molecular weight proteins ranging between 12-42 
kDa called Small Heat Shock Proteins (sHSPs) (Table $1)^{23}$. Hsps are expressed in stress and non-stress conditions while sHsps are mostly expressed under stress conditions ${ }^{24}$. It has been shown that most of the antifungal drugs are perceived as stress by the fungal cell ${ }^{25}$. Thus sHSPs can be explored as the putative targets to combat drug resistance and the development of effective therapeutics to treat fungal infections.

\section{Roles of Heat Shock Proteins (HSPs) in pathogenic} fungi

High molecular weight HSPs are the major proteins that are involved in protecting cellular proteins by acting as chaperons. HSPs in pathogenic fungi are assisting in the process of making and maintaining three dimensional conformations of proteins during various stress and unfavorable conditions to counter the changes in the fungal cells. Expression and functions of different Hsps are variable with the kind of stress to the fungal pathogen.

Hsp104

Hsp104 was firstly reported in Saccharomyces cerevisiae (S. cerevisiae) and induced in elevated temperature ${ }^{23,26,27}$. It also acts as a pro-survival protein under high temperature, suggesting its role as thermal tolerance ${ }^{26}$. Mutant of $h s p 104 \Delta / \Delta$ have shown morphological defects in hyphae ${ }^{28}$. In C. albicans, Hsp104 has a greater role in biofilm formation and virulence ${ }^{28}$. Cytosolic Hsp104 of C. albicans is not equivalent to human Hsp104, thus can be used as a promising antifungal target against $C$. albicans. Hsp90

Hsp90 determines antifungal drug resistance in several diseases causing fungi like Candida albicans, A. fumigatus, and $C$. neoformans ${ }^{29-31}$. Hsp90 is involved in several

Table 1. Different types of heat shock proteins (HSPs)

\begin{tabular}{|c|c|}
\hline $\begin{array}{c}\text { HSPs } \\
\text { (ATP-Dependent } \\
\text { High Molecular } \\
\text { Weight Proteins) }\end{array}$ & $\begin{array}{c}\text { sHSPs } \\
\text { (ATP-Independent } \\
\text { Low Molecular } \\
\text { Weight Proteins) }\end{array}$ \\
\hline Hsp104 & Hsp12 \\
\hline Hsp70 & Hsp21 \\
\hline Hsp60 & \\
\hline
\end{tabular}

cellular functions like development, regulation, homeostasis, and drug resistance in C. albicans ${ }^{16,17}$. $A$ recent report showed that mutations in the region of $\mathrm{Hsp} 90$, responsible for post-translational modifications affect colony morphology ${ }^{32}$. Inhibitors of Hsp90 function have shown additive effects with fluconazole (FLC) against Fluconazole resistant Candida albicans ${ }^{33,34}$. In yeast, the Hsp90 function is mediated by its C-terminal phosphorylation, S-nitrosylation, and acetylation ${ }^{35-37}$. Several findings showed that Hsp90 contributes a vital function in confirming resistance to antimycotic drugs. Thus inhibiting Hsp90 function or development of pathogen specific histone deacetylase inhibitor can be the effective therapeutics to treat candidiasis.

Hsp70

Hsp70 is uniformly present from prokaryotes like bacteria to higher eukaryotes like mammals. Ssa1 and Ssa2 are two important members of the Hsp70 family on the cell surface of C. albicans ${ }^{38,39}$. C. albicans Ssa1/1 mutant showed altered virulence in vitro as well as in vivo. Ssa1 and many antimicrobial peptides have Ssa2 as receptors that also have antifungal effects. Hsp70 alone or in combination with Hsp90 plays a major role in morphogenesis and dimorphism. A report have shown that the Hsp70 works with the heat shock transcription factor 1 (Hsf1) to regulate heat shock response in the yeast ${ }^{40}$.

Hsp60

Hsp60 encodes a predictive mitochondrial heat shock protein, whose function is not known. A heterozygous mutant of Hsp60 ( $h s p 60 \Delta / H S P 60)$ has been shown to increase sensitivity with increasing temperatures. This is an indication of Hsp60 can be essential to overcome thermal stress ${ }^{41}$. Four fold increased expression of hsp60 in wild type yeast can resist oxidative stress in comparison to the mutant of hsp60. It was because iron/sulfur containing enzymes were protected from oxidative inactivation ${ }^{42}$. Another study showed an increase in the levels of Hsp60 under thermal stress and is important for differentiation, infection, and colonization ${ }^{43}$. Expression of hsp 60 mRNA level increased by $5.9-6.9-$ foldat $40^{\circ} \mathrm{C}$ in $A$. fumigatus and $A$. terreus ${ }^{44}$. Hsp60 functions as an immunological trigger and play a role in fungal diseases in humans ${ }^{45}$. 
Role of Small Heat shock proteins (sHSPs) in $C$. albicans

Reports have shown that SHSPs of different species function as molecular chaperones and have conserved the $\alpha$-crystallin domain (ACD). sHsps are cellular chaperones, involve in the proper folding of proteins during normal and extreme conditions. Under stress conditions, sHSPs contribute in refolding of partially unfolded proteins. They bind to the irreversible aggregation of denaturing proteins and are prevented in an ATP-independent fashion ${ }^{46-49}$. Exposure to a variety of stresses like elevated temperature or oxidative stress causes unfolding of proteins and form early intermediates that can aggregates. These partially unfolding protein molecules are stabilized by the $\mathrm{SHSPs}^{48,50-52}$. Early expression of sHSPs allows rescuing proteins that are getting unfolded under stressed conditions. Completely unfolded proteins and pre-aggregated proteins are not refolded by
sHSPs. Thus, sHSPs protect unfolding proteins that otherwise become irreversible aggregates under stressful conditions to maintain homeostasis within the cell (Fig. 1).

Various studies have shown a link between HSPs and virulence potential of pathogenic microorganisms ${ }^{18,53-58}$ including $\mathrm{Hsp90}$ and Hsp70 in Candida albicans ${ }^{33,59}$. Biofilm formation is an important virulence phenomenon in $C$. albicans infection and HSPs are required for its progression ${ }^{14}$. In C. albicans have reported three sHSPs i.e. Hsp10, Hsp12, and Hsp30/Hsp31.

Hsp12

Small heat shock protein (Hsp12) contributes to heat-shock resistance and hybridization of hsp12 mRNA analysis demonstrated its co-regulation with environmental $\mathrm{pH}$ and $\mathrm{CO}_{2}$ in C. albicans ${ }^{60-63}$. Intracellular amount of trehalose (Protectant against cell freezing) was minimized in $C$. albicans by TPS1 deletion. TPS1 deletion

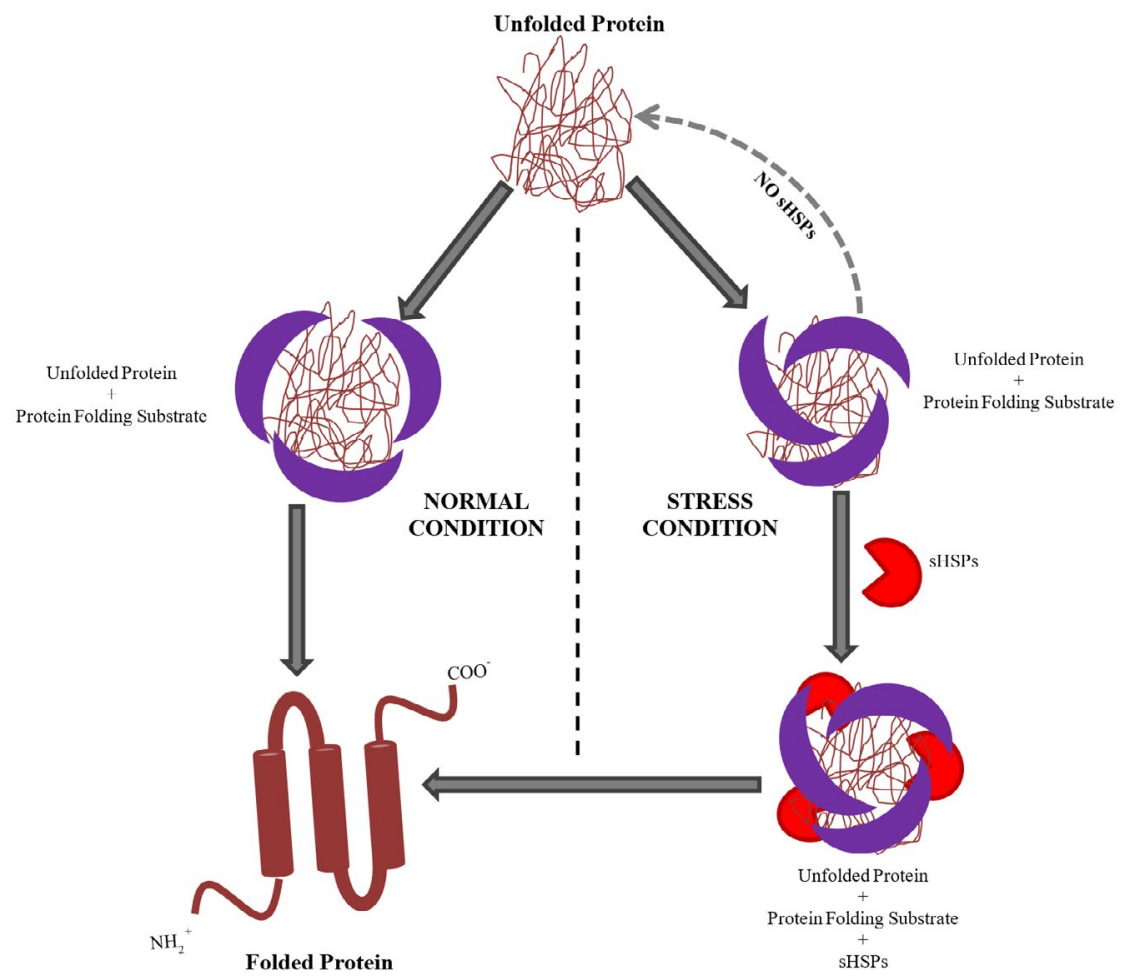

Fig 1. Model showing working of Small Heat Shock Proteins (sHSPs) system as chaperone. Protein folding is mediated by the cellular chaperon molecules(Protein folding substrate complex) which are active under the normal state of cell. sHSPs are expressed under the stress and they stabilize and assist the protein folding substrate complex to form proper confirmation and folding of the proteins. Loss of function of SHSPs in stress leads to formation of nonfunctional unfolded protein aggregates which can cause cell death, therefore sHSPs are rescuing cell under stress. 
showed overexpression of Hsp12 in C. albicans. C. albicans have shown increased cell adhesion and decrease susceptibility to the quorum sensing molecule, farnesol ${ }^{64,65}$. SSK1 mutant of $C$. albicans was susceptible to several oxidative agents like $\mathrm{H}_{2} \mathrm{O}_{2}$ and has also shown a high level of $\mathrm{HSP} 2^{66}$. This shows Hsp12p has a crucial role in combating various kinds of stresses. Another study showed that increased expression of Hsp12 leads to sensitivity to itraconazole, ketoconazole, and FLC in C. albicans ${ }^{65}$.

\section{Hsp21}

Small heat shock protein 21 (Hsp21p) is another protein which plays an important role under various environmental stress for $C$. albicans $^{61,67-72}$. It was found that Hsp21 promotes virulence of $C$. albicans. Tolerance to heat and oxidative stress requires Hsp21 in C. albicans ${ }^{73}$. Activation of the mitogen activated protein (MAP) kinase and normal filamentation require Hsp21. Hsp21 mutant and chemical inhibitors have shown a correlation in inhibiting germ tube formation and filamentation at the initial time point ${ }^{73}$. In-vitro, analysis of $h s p 21 \Delta / \Delta$ mutant strain showed an inability to damage endothelial and oral epithelial cells ${ }^{73}$. Growth of Hsp21 mutant was significantly reduced when treated with membrane perturbing agents that target ergosterol biosynthetic pathway i.e. terbinafine, caspofungin ${ }^{73}$. At high temperatures, it is involved in maintaining homeostasis of glycerol, glycogen, and trehalose $\mathrm{e}^{73}$. Susceptibility to various antifungal drugs was seen in the deletion mutant of hsp21of C. albicans $^{74}$. Hsp21 can be an effective target to develop a treatment strategy for $C$. albicans infection.

\section{Hsp10}

Hsp10p is present in association with Hsp60p and assisting Hsp60 function ${ }^{75}$. In-vivo Hsp60p and Hsp10p did not always act as a single functional unit in-vitro. Hsp10p is crucial for cell survival and acting as a co-chaperon to assist the folding of the proteins in the mitochondrial matrix ${ }^{76}$. Functionally defective protein aggregation was seen in the mutant of Hsp10. It imparts in the sorting of the RieskeFeS protein during the transport from the matrix to the intermembrane space ${ }^{77}$.

Hsp30/31

In C. albicans, oxidative stress upregulates
Hsp30p besides other heat shock proteins ${ }^{61}$. A gene of $A$. nidulans, Hsp30 is homologous to the Hsp26 gene of Saccharomyces cerevisiae and found upregulated in numerous stress conditions including low $\mathrm{pH}^{18,78}$. In another study, Iron deprivation is sensed as the nutritional deficiency in Candida cells, leading to the upregulation of $\mathrm{Hsp} 3 \mathrm{p}^{79}$.

Targeting small heat shock proteins (sHSPs) can be an effective combat strategy to overcome drug resistance in pathogenic fungi. Sequence alignment analysis of sHSPs showed no similarity in the nucleotides or protein sequences with that of humans (data not shown). Understanding sHSPs and its interactive partners not only allow us to study drug resistance but also can be the promising lead therapeutic molecules. It will be an interesting study to see their expression pattern during the progression of drug resistance in pathogenic fungi.

\section{DISCUSSION}

Pathogenic fungi are a major cause of secondary infection and hospital-acquired infections. Drug resistance in fungi is the major setback in the treatment of these infections. Several studies have shown the promising role of sHSPs as novel targets to develop an effective treatment against these drug resistant fungal infections. A study showed that potential antifungal treatment of $C$. albicans is achieved by over-expressing $\mathrm{Hsp} 12^{65}$. Role of Hsp10 and Hsp30/Hsp31 are still not very clear, while on the other hand it will be fascinating to find the crucial function of Hsp21 in the understanding of antifungal drug resistance development. Hsps are not only playing vital roles in many major cellular pathways, such as calcium-calcineurin, MAPK, Ras1-cAMP-PKA, and cell cycle control signaling but several client proteins of Hsps are signaling molecules. Moreover, different groups have reported the involvement of Hsps to confer antifungal drug resistance by modulating these signaling pathways in C. albicans. Thus, developing new effective antifungal targets are required to investigate HSPs and other signaling molecules of HSPs-associated pathways in C. albicans. Therefore, the study of HSPs expression and the functional role will help us better in exploring 
not only their roles as chaperones but also their indulgent in disease development and progression caused by fungal parasites.

\section{CONCLUSION}

This review summarizes some of the explored functions of sHSPs in direction of drug resistance in fungal biology and indicating that available information is insufficient to understand the in-depth role of these SHSPs in drug resistance. Hence sHSPs provide a new horizon to explore the unexplored heat shock molecules to understand their regulation and function in the interactome of cell molecules and could be promising targets to develop new therapeutics to combat drug resistance in pathogenic fungi. Moreover sHsps have not been given enough attention for a long time to understand their biological roles and targeting them for therapeutic use for overcoming fungal drug resistance.

\section{ACKNOWLEDGMENTS}

The author is thankful to Department of Zoology, Acharya Narendra Dev College, University of Delhi.

\section{FUNDING}

None.

\section{DATA AVAILABILITY}

All datasets generated or analyzed during this study are included in the manuscript.

\section{ETHICS STATEMENT}

Not applicable.

\section{REFERENCES}

1. Dimopoulos G, Karabinis A, Samonis G, Falagas ME. Candidemia in immunocompromised and immunocompetent critically ill patients: a prospective comparative study. Eur J Clin Microbiol Infect Dis.: The official publication of the European Society of Clinical Microbiology and Infectious Diseases. 2007;26:377384. doi: 10.1007/s10096-007-0316-2

2. Odds FC, Brown AJ, Gow NA. Antifungal agents: mechanisms of action. Trends in Microbiology. 2003;11:272-279. doi: 10.1016/s0966842X(03)00117-3

3. Monge RA, Roman E, Nombela C, Pla J. The MAP kinase signal transduction network in Candida albicans. Microbiology. 2006;152:905-912. doi: 10.1099/ mic.0.28616-0

4. Steinbach WJ, Reedy JL, Cramer RAJr, Perfect JR,
Heitman J. Harnessing calcineurin as a novel antiinfective agent against invasive fungal infections. Nat Rev Microbiol. 2007;5:418-430. doi: 10.1038/ nrmicro1680

5. Sanglard D, Ischer F, Marchetti O, Entenza J, Bille J. Calcineurin A of Candida albicans: involvement in antifungal tolerance, cell morphogenesis and virulence. Molecular Microbiology. 2003;48:959-976. doi: 10.1046/j.1365-2958.2003.03495.x

6. Perepnikhatka V, Fischer FJ, Niimi M, et al. Specific chromosome alterations in fluconazole-resistant mutants of Candida albicans. Journal of Bacteriology. 1999;181:4041-4049. doi: 10.1128/JB.181.13.40414049.1999

7. Selmecki A, Forche A, Berman J. Aneuploidy and isochromosome formation in drug-resistant Candida albicans. Science. 2006;313:367-370. doi: 10.1126/ science. 1128242

8. Cowen LE, Sanglard D, Howard SJ, Rogers PD, Perlin DS. Mechanisms of Antifungal Drug Resistance. Cold Spring Harb Perspect Med. 2014;5:a019752. doi: 10.1101/ cshperspect.a019752

9. Kriengkauykiat J, Ito JI, Dadwal SS. Epidemiology and treatment approaches in management of invasive fungal infections. Clinical epidemiology. 2011;3:175191. doi: 10.2147/CLEP.S12502

10. Wirk B, Wingard JR. Assessing responses to treatment of opportunistic mycoses and salvage strategies. Current Infectious Disease Reports. 2011;13:492-503. doi: 10.1007/s11908-011-0217-5

11. Cuenca-Estrella M. Antifungal drug resistance mechanisms in pathogenic fungi: from bench to bedside. Clinical microbiology and infection : the official publication of the European Society of Clinical Microbiology and Infectious Diseases. 2014;20(Suppl 6):54-59. doi: 10.1111/1469-0691.12495

12. Veri AO, Robbins N, Cowen LE. Regulation of the heat shock transcription factor Hsf1 in fungi: implications for temperature-dependent virulence traits. FEMS Yeast Research. 2018;18. doi: 10.1093/femsyr/foy041

13. Leach MD, Tyc KM, Brown AJ, Klipp E. Modelling the regulation of thermal adaptation in Candida albicans, a major fungal pathogen of humans. PIOS ONE. 2012;7:e32467. doi: 10.1371/journal.pone.0032467

14. Becherelli M, Tao J, Ryder NS. Involvement of heat shock proteins in Candida albicans biofilm formation. Journal of Molecular Microbiology and Biotechnology. 2013;23:396-400. doi: 10.1159/000351619

15. Shapiro RS, Zaas AK, Betancourt-Quiroz M, Perfect JR, Cowen LE. The Hsp90 co-chaperone Sgt1 governs Candida albicans morphogenesis and drug resistance. PIOS ONE. 2012;7:e44734. doi: 10.1371/journal. pone.0044734

16. Leach MD, Klipp E, Cowen LE, Brown AJ. Fungal Hsp90: a biological transistor that tunes cellular outputs to thermal inputs. Nat Rev Microbiol. 2012;10:693-704. doi: $10.1038 / \mathrm{nrmicro} 2875$

17. O'Meara TR, Cowen LE. Hsp90-dependent regulatory circuitry controlling temperature-dependent fungal development and virulence, Cell Microbiol. 2014;16:473-481. doi: 10.1111/cmi.12266

18. Burnie JP, Carter TL, Hodgetts SJ, Matthews RC. 
Fungal heat-shock proteins in human disease. FEMS Microbiology Reviews. 2006;30:53-88. doi: 10.1111/j.1574-6976.2005.00001.x

19. Wirk B. Heat shock protein inhibitors for the treatment of fungal infections. Recent Patents on Anti-infective Drug Discovery. 2011;6:38-44. doi: 10.2174/157489111794407840

20. Basha E, O'Neill H, Vierling E. Small heat shock proteins and alpha-crystallins: dynamic proteins with flexible functions. Trends in Biochemical Sciences. 2012;37:106-117. doi: 10.1016/j.tibs.2011.11.005

21. Lopes-Caitar VS, de Carvalho MC, Darben LM, et al. Genome-wide analysis of the Hsp20 gene family in soybean: comprehensive sequence, genomic organization and expression profile analysis under abiotic and biotic stresses. BMC Genomics. 2013;14:577. doi: 10.1186/1471-2164-14-577

22. Lindquist S. The heat-shock response. Annual Review of Biochemistry. 1986;55:1151-1191. doi: 10.1146/ annurev.bi.55.070186.005443

23. Jaya N, Garcia V, Vierling E. Substrate binding site flexibility of the small heat shock protein molecular chaperones. Proceedings of the National Academy of Sciences of the United States of America. 2009;106:15604-15609. doi: 10.1073/ pnas. 0902177106

24. Narberhaus F. Alpha-crystallin-type heat shock proteins: socializing minichaperones in the context of a multichaperone network. Microbiol Mol Biol Rev.: MMBR. 2002;66:64-93. doi: 10.1128/MMBR.66.1.6493.2002

25. Cannon RD, Lamping E, Holmes AR, Niimi K, Tanabe K, Niimi M, Monk BC. Candida albicans drug resistance another way to cope with stress. Microbiology. 2007;153:3211-3217. doi: 10.1099/ mic.0.2007/010405-0

26. Sanchez Y, Lindquist SL. HSP104 required for induced thermotolerance. Science. 1990;248:1112-1115. doi: $10.1126 /$ science. 2188365

27. Glover JR, Lindquist S. Hsp104, Hsp70, and Hsp40: a novel chaperone system that rescues previously aggregated proteins. Cell. 1998;94:73-82. doi: 10.1016/S0092-8674(00)81223-4

28. Fiori A, Kucharikova S, Govaert G, Cammue BP, Thevissen K, Van Dijck P. The heat-induced molecular disaggregase Hsp104 of Candida albicans plays a role in biofilm formation and pathogenicity in a worm infection model. Eukaryotic cell. 2012;11:1012-1020. doi: 10.1128/EC.00147-12

29. Chatterjee $S$, Tatu U. Heat shock protein 90 localizes to the surface and augments virulence factors of Cryptococcus neoformans. PLoS Neglected Tropical Diseases. 2017;11:e0005836. doi: 10.1371/journal. pntd.0005836

30. Cordeiro Rde A, Evangelista AJ, Serpa R, et al. Inhibition of heat-shock protein 90 enhances the susceptibility to antifungals and reduces the virulence of Cryptococcus neoformans/Cryptococcus gattii species complex. Microbiology. 2016;162:309-317. doi: 10.1099/ mic. 0.000222

31. Lamoth F, Juvvadi PR, Steinbach WJ. Heat shock protein 90 (Hsp90): A novel antifungal target against
Aspergillus fumigatus. Critical Reviews in Microbiology. 2016;42:310-21.

32. Weissman Z, Pinsky M, Wolfgeher DJ, Kron SJ, Truman AW, Kornitzer D. Genetic analysis of Hsp70 phosphorylation sites reveals a role in Candida albicans cell and colony morphogenesis. Biochimica et Biophysica Acta Proteins and Proteomics. 2020;1868:140135. doi: 10.1016/j.bbapap.2018.09.001

33. Cowen LE, Singh SD, Kohler JR, et al. Harnessing Hsp90 function as a powerful, broadly effective therapeutic strategy for fungal infectious disease. Proceedings of the National Academy of Sciences of the United States of America. 2009;106:2818-2823. doi: 10.1073/ pnas.0813394106

34. Li L, An M, Shen $H$, et al. The non-Geldanamycin Hsp90 inhibitors enhanced the antifungal activity of fluconazole. American Journal of Translational Research. 2015;7:2589-2602.

35. Soroka J, Wandinger SK, Mausbacher N, et al. Conformational switching of the molecular chaperone Hsp90 via regulated phosphorylation. Molecular Cell. 2012;45:517-528. doi: 10.1016/j.molcel.2011.12.031

36. Martinez-Ruiz A, Villanueva L, Gonzalez de Orduna C, et al. S-nitrosylation of Hsp90 promotes the inhibition of its ATPase and endothelial nitric oxide synthase regulatory activities. Proc Natl Acad SciU SA. 2005;102:8525-8530. doi: 10.1073/pnas.0407294102

37. Retzlaff M, Stahl M, Eberl HC, et al. Hsp90 is regulated by a switch point in the C-terminal domain. EMBO Reports. 2009;10:1147-1153. doi: 10.1038/ embor.2009.153

38. Lopez-Ribot JL, Alloush HM, Masten BJ, Chaffin WL. Evidence for presence in the cell wall of Candida albicans of a protein related to the hsp70 family. Infection and Immunity. 1996;64:3333-3340. doi: 10.1128/IAI.64.8.3333-3340.1996

39. Eroles P, Sentandreu M, Elorza MV, Sentandreu R. The highly immunogenic enolase and Hsp70p are adventitious Candida albicans cell wall proteins. Microbiology. 1997;143(Pt 2):313-320. doi: 10.1099/00221287-143-2-313

40. Krakowiak J, Zheng X, Patel N, et al. Hsf1 and Hsp70 constitute a two-component feedback loop that regulates the yeast heat shock response. eLife. 2018;7. doi: 10.7554/elife. 31668

41. Leach MD, Stead DA, Argo E, Brown AJ. Identification of sumoylation targets, combined with inactivation of SMT3, reveals the impact of sumoylation upon growth, morphology, and stress resistance in the pathogen Candida albicans. Molecular Biology of the Cell. 2011;22:687-702. doi: 10.1091/mbc.e10-07-0632

42. Cabiscol E, Belli G, Tamarit J, Echave P, Herrero E, Ros J. Mitochondrial Hsp60, resistance to oxidative stress, and the labile iron pool are closely connected in Saccharomyces cerevisiae. The Journal of Biological Chemistry. 2002;277:44531-44538. doi: 10.1074/jbc. M206525200

43. Cunha DA, Zancope-Oliveira RM, Sueli M, et al. Heterologous expression, purification, and immunological reactivity of a recombinant HSP60 from Paracoccidioides brasiliensis. Clin Diagn Lab Immunol. 2002;9:374-377. doi: 10.1128/CDLI.9.2.374-377.2002 
44. Raggam RB, Salzer HJ, Marth E, Heiling B, Paulitsch AH, Buzina W. Molecular detection and characterisation of fungal heat shock protein 60 . Mycoses. 2011;54:e394-e399. doi: 10.1111/j.14390507.2010.01933.x

45. Sonna LA, Hawkins L, Lissauer ME, et al. Core temperature correlates with expression of selected stress and immunomodulatory genes in febrile patients with sepsis and noninfectious SIRS. Cell Stress \& Chaperones. 2010;15:55-66. doi: 10.1007/s12192009-0121-1

46. de Jong WW, Leunissen JA, Voorter CE. Evolution of the alpha-crystallin/small heat-shock protein family. Mol Biol Evol. 1993;10:103-126.

47. Jakob U, Gaestel M, Engel K, Buchner J. Small heat shock proteins are molecular chaperones. The Journal of Biological Chemistry. 1993;268:1517-1520.

48. McHaourab HS, Dodson EK, Koteiche HA. Mechanism of chaperone function in small heat shock proteins. Two-mode binding of the excited states of T4 lysozyme mutants by alphaA-crystallin. The Journal of Biological Chemistry. 2002;277:40557-40566. doi: 10.1074/jbc. M206250200

49. Haslbeck M, Walke S, Stromer T, et al. Hsp26: a temperature-regulated chaperone. The EMBO Journal. 1999;18:6744-6751. doi: 10.1093/emboj/18.23.6744

50. Bepperling A, Alte $F$, Kriehuber T, et al. Alternative bacterial two-component small heat shock protein systems. Proc Natl Acad Sci USA. 2012;109:2040720412. doi: $10.1073 /$ pnas.1209565109

51. Haslbeck M, Braun N, Stromer T, et al. Hsp42 is the general small heat shock protein in the cytosol of Saccharomyces cerevisiae. The EMBO Journal. 2004;23:638-649. doi: 10.1038/sj.emboj.7600080

52. McHaourab HS, Godar JA, Stewart PL. Structure and mechanism of protein stability sensors: chaperone activity of small heat shock proteins. Biochemistry. 2009;48:3828-3837. doi: 10.1021/bi900212j

53. Kaufmann $\mathrm{SH}$. Heat-shock proteins and pathogenesis of bacterial infections. Springer Seminars in Immunopathology. 1991;13:25-36. doi: 10.1007/ BF01225276

54. Yamaguchi H, Osaki T, Taguchi H, Hanawa T, Yamamoto $\mathrm{T}$, Kamiya S. Flow cytometric analysis of the heat shock protein 60 expressed on the cell surface of Helicobacter pylori. J Med Microbiol. 1996;45:270-277. doi: 10.1099/00222615-45-4-270

55. Hubel A, Krobitsch S, Horauf A, Clos J. Leishmania major Hsp100 is required chiefly in the mammalian stage of the parasite. Mol Cell Biol. 1997;17:5987-5995. doi: 10.1128/MCB.17.10.5987

56. Meibom KL, Dubail I, Dupuis M, et al. The heatshock protein ClpB of Francisella tularensis is involved in stress tolerance and is required for multiplication in target organs of infected mice. Molecular Microbiology. 2008;67:1384-1401. doi: 10.1111/j.1365-2958.2008.06139.x

57. de Koning-Ward TF, Gilson PR, Boddey JA, et al. A newly discovered protein export machine in malaria parasites. Nature. 2009;459:945-949. doi: 10.1038/ nature08104

58. Shonhai A. Plasmodial heat shock proteins: targets for chemotherapy. FEMS Immunology and Medical Microbiology. 2010;58:61-74. doi: 10.1111/j.1574695X.2009.00639.x

59. Sun JN, Solis NV, Phan QT, et al. Host cell invasion and virulence mediated by Candida albicans Ssa1. PLOS Pathogens. 2010;6:e1001181. doi: 10.1371/journal. ppat.1001181

60. Pacheco A, Pereira C, Almeida MJ, Sousa MJ. Small heatshock protein $\mathrm{Hsp} 12$ contributes to yeast tolerance to freezing stress. Microbiology. 2009;155:2021-2028. doi: 10.1099/mic.0.025981-0

61. Enjalbert B, Nantel A, Whiteway M. Stress-induced gene expression in Candida albicans: absence of a general stress response. Molecular Biology of the Cell. 2003;14:1460-1467. doi: 10.1091/mbc.e02-08-0546

62. Smith DA, Nicholls S, Morgan BA, Brown AJ, Quinn J. A conserved stress-activated protein kinase regulates a core stress response in the human pathogen Candida albicans. Molecular Biology of the Cell. 2004;15:41794190. doi: 10.1091/mbc.e04-03-0181

63. Sheth CC, Mogensen EG, Fu MS, Blomfield IC, Muhlschlegel FA. Candida albicans HSP12 is coregulated by physiological $\mathrm{CO} 2$ and $\mathrm{pH}$. Fungal Genetics and Biology : FG \& B. 2008;45:1075-1080. doi: 10.1016/j.fgb.2008.04.004

64. Davis-Hanna A, Piispanen AE, Stateva LI, Hogan DA. Farnesol and dodecanol effects on the Candida albicans Ras1-cAMP signalling pathway and the regulation of morphogenesis. Molecular Microbiology. 2008;67:4762. doi: 10.1111/j.1365-2958.2007.06013.x

65. Fu MS, De Sordi L, Muhlschlegel FA. Functional characterization of the small heat shock protein $\mathrm{Hsp} 12 \mathrm{p}$ from Candida albicans, PloS ONE. 2012;7:e42894. doi: 10.1371/journal.pone.0042894

66. Vianna RN, Souza Filho JP, Deschenes J, Burnier MNJr. Bilateral Candida chorioretinitis: involvement of the second eye after 3 years. Journal Canadien d'ophtalmologie. 2005;40:75-78. doi: 10.1016/S00084182(05)80122-X

67. Nicholls $S$, Leach MD, Priest $C L$, Brown AJ. Role of the heat shock transcription factor, Hsf1, in a major fungal pathogen that is obligately associated with warm-blooded animals. Molecular Microbiology. 2009;74:844-861. doi: 10.1111/j.13652958.2009.06883.x

68. Enjalbert B, Moran GP, Vaughan C, et al. Genomewide gene expression profiling and a forward genetic screen show that differential expression of the sodium ion transporter Ena21 contributes to the differential tolerance of Candida albicans and Candida dubliniensis to osmotic stress. Molecular Microbiology. 2009;72:216-228. doi: 10.1111/j.13652958.2009.06640.x

69. Ramsdale M, Selway L, Stead D, et al. MNL1 regulates weak acid-induced stress responses of the fungal pathogen Candida albicans. Molecular Biology of the Cell. 2008;19:4393-4403. doi: 10.1091/mbc.e07-090946

70. Lorenz MC, Bender JA, Fink GR. Transcriptional response of Candida albicans upon internalization by macrophages, Eukaryotic Cell. 2004;3:1076-1087. doi: 10.1128/EC.3.5.1076-1087.2004 
71. Thewes S, Kretschmar M, Park H, Schaller M, Filler SG, Hube B. In vivo and ex vivo comparative transcriptional profiling of invasive and non-invasive Candida albicans isolates identifies genes associated with tissue invasion. Molecular Microbiology. 2007;63:1606-1628. doi: 10.1111/j.1365-2958.2007.05614.x

72. Fradin C, De Groot P, MacCallum D, et al. Granulocytes govern the transcriptional response, morphology and proliferation of Candida albicans in human blood. Molecular Microbiology. 2005;56:397-415. doi: 10.1111/j.1365-2958.2005.04557.x

73. Mayer FL, Wilson D, Jacobsen ID, et al. Small but crucial: the novel small heat shock protein Hsp21 mediates stress adaptation and virulence in Candida albicans, PLOS ONE. 2012;7:e38584. doi: 10.1371/journal. pone. 0038584

74. Mayer FL, Wilson D, Hube B. Hsp21 potentiates antifungal drug tolerance in Candida albicans. PloS ONE. 2013;8:e60417. doi: 10.1371/journal. pone.0060417

75. Dubaquie $Y$, Looser R, Rospert S. Significance of chaperonin 10-mediated inhibition of ATP hydrolysis by chaperonin 60. Proc Natl Acad Sci USA. 1997;94:90119016. doi: 10.1073/pnas.94.17.9011

76. Miura T, Minegishi H, Usami R, Abe F. Systematic analysis of HSP gene expression and effects on cell growth and survival at high hydrostatic pressure in Saccharomyces cerevisiae. Extremophiles: Life Under Extreme Conditions. 2006;10:279-284. doi: 10.1007/ s00792-005-0496-6

77. Hohfeld J, Hartl FU. Role of the chaperonin cofactor Hsp10 in protein folding and sorting in yeast mitochondria. The Journal of Cell Biology. 1994;126:305-315. doi: 10.1083/jcb.126.2.305

78. Amoros M, Estruch F. Hsf1p and Msn2/4p cooperate in the expression of Saccharomyces cerevisiae genes HSP26 and HSP104 in a gene- and stress type-dependent manner. Molecular Microbiology. 2001;39:1523-1532. doi: 10.1046/j.1365-2958.2001.02339.x

79. Hameed S, Prasad T, Banerjee D, et al. Iron deprivation induces EFG1-mediated hyphal development in Candida albicans without affecting biofilm formation. FEMS Yeast Research. 2008;8:744-755. doi: 10.1111/j.1567-1364.2008.00394.x 